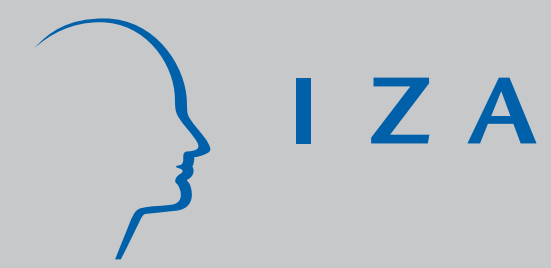

IZA DP No. 7113

Simulating the Economic Impacts of Living Wage Mandates Using New Public and Administrative Data: Evidence for New York City

David Neumark

Matthew Thompson

Francesco Brindisi

December 2012
Leslie Koyle

Clayton Reck 


\title{
Simulating the Economic Impacts of Living Wage Mandates Using New Public and Administrative Data: Evidence for New York City
}

\author{
David Neumark \\ $U C I, N B E R$ and IZA
}

Matthew Thompson
Charles River Associates

\section{Francesco Brindisi}

New York City Office of

Management and Budget

\author{
Leslie Koyle \\ Charles River Associates \\ Clayton Reck \\ Charles River Associates
}

\author{
Discussion Paper No. 7113 \\ December 2012
}

IZA
P.O. Box 7240
53072 Bonn
Germany

Phone: +49-228-3894-0

Fax: +49-228-3894-180

E-mail: iza@iza.org

\begin{abstract}
Any opinions expressed here are those of the author(s) and not those of IZA. Research published in this series may include views on policy, but the institute itself takes no institutional policy positions. The IZA research network is committed to the IZA Guiding Principles of Research Integrity.

The Institute for the Study of Labor (IZA) in Bonn is a local and virtual international research center and a place of communication between science, politics and business. IZA is an independent nonprofit organization supported by Deutsche Post Foundation. The center is associated with the University of Bonn and offers a stimulating research environment through its international network, workshops and conferences, data service, project support, research visits and doctoral program. IZA engages in (i) original and internationally competitive research in all fields of labor economics, (ii) development of policy concepts, and (iii) dissemination of research results and concepts to the interested public.
\end{abstract}

IZA Discussion Papers often represent preliminary work and are circulated to encourage discussion. Citation of such a paper should account for its provisional character. A revised version may be available directly from the author. 


\section{ABSTRACT \\ Simulating the Economic Impacts of Living Wage Mandates Using New Public and Administrative Data: Evidence for New York City}

Policy researchers often have to estimate the future effect of imposing a policy in a particular location. There is often evidence on the effects of similar policies in other jurisdictions, but no information on the effects of the policy in the jurisdiction in question. And the policy may have specific features not reflected in the experiences of other areas. It is then necessary to combine the evidence from other locations with detailed information and data specific to the jurisdiction in question, with which to simulate the effects of the policy in the new jurisdiction. We illustrate and use this approach in estimating the impact of a proposed living wage mandate for New York City, emphasizing how our ex ante simulations make use of detailed location-specific information on workers, families, and employers using administrative data and other new public data sources.

JEL Classification: J23, J38, R51

Keywords: living wage, employment, poverty

Corresponding author:

David Neumark

Department of Economics

3151 Social Science Plaza

University of California, Irvine

Irvine, CA 92697

USA

E-mail:dneumark@uci.edu

\footnotetext{
* This paper is drawn from a larger study conducted by Charles River Associates, funded by the New York City Economic Development Corporation (Charles River Associates, 2011). The views expressed are those of the authors and do not reflect the views of Charles River Associates, the City of New York, its Office of Management and Budget, or the New York City Economic Development Corporation. We are grateful to Daniel Hamermesh for many helpful comments and to Marsha Courchane, Timothy Riddiough, and Anthony Yezer for collaboration on the larger project.
} 


\section{Introduction}

With the advent of the living wage movement in the early 1990s, labor economists and other policy analysts have often been asked to estimate the future effects of imposing a local wage mandate in a city. Lacking an historical record, studies for the cities that implemented living wages early relied on ex ante simulations using some existing data and survey evidence, coupled with assumptions about the effects of the mandates (e.g., Pollin \& Luce, 1998). As more local governments adopted living wage laws, "before-and-after" (longitudinal) evidence became available (e.g., Neumark \& Adams, 2003), although the experience of other cities may not capture specific features of a given city's economic landscape or specifics of a proposed law.

In 2010, a proposal (Intro. 251) was introduced to significantly expand New York City's existing very narrow contractor-only living wage law to a broad "business assistance" living wage law intended to cover firms and real property receiving financial assistance from the City for economic development. The law would have covered employees, contractors, and subcontractors hired by the direct recipients of financial assistance, and tenants and sub-tenants, establishing a wage floor of $\$ 10$ per hour, or $\$ 11.50$ if health insurance was not provided. ${ }^{1}$

The New York City Economic Development Corporation (NYCEDC) commissioned a comprehensive study to estimate the effects that Intro. 251 would have on labor and real estate markets (Charles River Associates, 2011). The estimates are derived from ex ante simulations specific to New York City, but the parameters used are informed by new longitudinal estimates for other cities. The longitudinal estimates of the effects of living wages in other cities provide the best information we have on the actual effects of living wage laws that have been implemented. At the same time, there are limits to what we can learn about the potential effects of a living wage law in New York City from studying the experiences of other cities, because the law proposed for New York City had unique features, and the evidence from before-and-after 
analyses for other cities may be less applicable to New York City because it is such a large, complex, and, in many ways, unique labor market.

Thus, we conducted detailed simulations of the effects of the proposed living wage law mandate in New York City, using highly detailed data for New York City that captures features of the labor market and the proposed law in a realistic way. Nonetheless, one needs to make assumptions about behavioral responses to do the simulation - in particular, for the employment effect of a living wage mandate - and it seems best to rest such assumptions, where possible, on estimates from observed changes in behavior.

The simulation analysis presents a number of innovations relative to the earlier ex ante simulations, based on new data and sources of information, including extensive historical data on recipients of financial assistance from the city, employer-level data for New York City from the Quarterly Census of Employment and Wages, and data on place of work and residence, and other information, from the relatively new American Community Survey. This paper highlights the simulation analysis and the role these innovations play in the analysis.

Living wages have been and remain a contentious and politically charged topic, and the reception of this study was no exception. ${ }^{2}$ Much of the debate focuses on the estimation of the wage and employment effects of living wages that are central inputs into the simulations. The purpose of this paper is not to revisit this debate, although many of the estimates presented rely on the methods that have been subject to debate. Our new longitudinal estimates based on other cities are not the focus of the paper; readers are referred to Neumark, Thomson, Brindisi, Koyle, and Reck (2012) for details and an extensive discussion of the debate over these methods. ${ }^{3}$ The methods used in the simulations can be applied to other cities, whether using our longitudinal methods and estimates, or other estimates or assumptions regarding behavioral responses.

Nor is the goal of this paper to argue about the actual effects of proposed legislation that 
has been substantially revised and, though subject to ongoing litigation, went into effect at the end of September 2012. From a research perspective, this would be of little relevance, and confirmation or rejection of our simulation results ultimately requires ex post observations on the outcomes we simulate. Rather, the goal of this paper is to present to researchers and practitioners the comprehensive methods and data sources that, in our view, can and should be used to evaluate the prospective effects of living wage policies. ${ }^{4}$ We describe the results of our analysis along the way, to illustrate and explain our methods, while recognizing that other researchers, even following our approach, might do things differently and reach different answers. Regardless, we believe the methods and data we use provide a template for more thorough and compelling predictions of the effects of living wage mandates, and of related policies for which the data and methods are appropriate.

\section{Simulating the Effects of the Living Wage in New York City}

Evaluating the likely effects of New York City's living wage law required elements of an ex ante analysis to account for the uniqueness of the city and the proposed legislation. At the same time, evidence on the effects of living wages in other cities provides the best information on the actual effects of laws that have been implemented. Thus, we conducted an updated longitudinal analysis of living wages laws in U.S. cities to estimate the behavioral responses, and coupled this with rich, new data sources to try to capture as accurately as possible the specific features of New York City's labor market. In the next subsection we briefly describe the results of the longitudinal analysis of other cities, before turning in detail to simulations for New York City.

\section{Estimated Effects on Low-Wage Workers and Low-Income Families}

The estimation of the effects of living wage laws in other cities relies on monthly Current Population Survey (CPS) files to study workers, and the annual March CPS files to study 
families. We use the methods from Adams and Neumark (2005b), updated as far as 2009. There were a number of complications stemming from changes in the classification of geographic areas in the CPS. Details are provided in Neumark et al. (2012). That same paper also presents a lengthy discussion of earlier criticisms of the research using the CPS data to estimate the effects of living wage laws, concluding that the CPS data and the methods used give valid results. Regardless, the emphasis in this paper is on how these estimated effects get used in the simulation study, so researchers or policy analysts can easily substitute their own preferred estimates, or a range of estimates or assumptions.

The analysis also required information on living wage laws. Cities are the political units that adopt most living wage laws. We characterized the living wage laws prevailing in a metropolitan area based on the living wages passed by the major cities in the MSA, which was also complicated by the changes in geographic classification. We engaged in extensive research to recover the needed historical information on living wage laws. Using this information, we coded the wage levels for the major cities in our analysis sample with living wages, for each year and month from January 1995 through December $2009 .{ }^{5}$ We also coded whether or not the living wage law applies to business assistance recipients, or only to contractors.

This analysis leads to elasticities of wages and employment of low-skilled workers and individuals with respect to living wages, which we use in the simulation analysis that follows. The elasticity estimates we use come from the evidence on living wage laws in other cities that cover employers who receive financial or business assistance from the city, paralleling the proposed New York City living wage law. ${ }^{6}$ Our preferred estimated wage elasticity 0.051 (not statistically significant, but the positive finding is robust across many specifications and samples, and significant in some). This elasticity applies to workers in the bottom decile of the wage distribution. However, as explained below, we do not rely explicitly on this wage elasticity in 
the simulation, because we have detailed wage data and information on employers targeted by the proposal, so we can directly estimate the effect of topping covered workers up to the living wage. The estimated employment elasticity, in contrast, is a key input into the simulation. The estimated employment elasticity with respect to business assistance living wages that we prefer based on our analysis is -0.055 (statistically significant at the $5 \%$ level). This is estimated for those in the bottom decile of the predicted wage distribution. Our analysis indicated that the wage and employment effects of living wages fall on these lowest-skilled workers, and hence that their effects on the distribution of family incomes stem mainly from the effects of living wages on the lowest-wage and lowest-skilled workers. As a result, in the simulations for New York City below, we focus only on effects on the lowest-wage, lowest-skilled workers. ${ }^{7}$

Past research on living wages in other cities has also studied the effects of living wages on family income, and in particular the probability that a family is poor. These estimated effects capture the distribution of wage and employment (and hours) effects on families at different points of the income distribution. Again, the methods follow Adams and Neumark (2005b), and details are provided in Neumark et al. (2012). This analysis arrives at a preferred estimated effect of -0.035 , which implies, for example, that a $100 \%$ increase in a business assistance living wage reduces the poverty rate by 3.5 percentage points (again not statistically significant, but positive across many specifications and samples, and significant in some). However, in the simulation study we do not apply this elasticity directly, preferring to use the rich information we have on wages in New York City, coupled with our estimated employment elasticity, to directly simulate the effects on the family income distribution. Nonetheless, this estimate is useful as a comparison to our simulation results.

\section{Simulation Study}

We establish a baseline for our simulation by providing a detailed description of workers 
and families that could be affected by the proposed living wage law, and then project how they would be affected. We use multiple inputs, including data on New York City workers, families, and business establishments, estimates of effects of living wage laws that are broadly applicable to New York City, and information on income-support and other programs available to New York City residents and how eligibility and benefit levels are determined. The estimates of behavioral responses to living wage laws, where appropriate, come from the analyses described briefly above. The other inputs - including the data used for New York City - are described next.

\section{$\underline{\text { Data and Measurement }}$}

The American Community Survey (ACS) contains detailed information on where people live and work, and can therefore be used to construct a detailed portrait of the New York City workforce and the population affected by the proposed living wage law. We also use the ACS to identify workers based on their wage levels, their industry and borough of employment, their place of residence, and the characteristics of other members of their families; the latter is used for simulating the effects on the distribution of family incomes. We use the three-year ACS sample covering 2006-2008, which collects yearly data re-weighted to yield average values over the sample period.

To identify workers directly affected by the proposed living wage, we had to identify covered work sites and obtain information about workers and earnings at these sites. Typically, tax expenditures for economic development in New York City are tied to construction or renovation of real estate. Various programs in place exempt the taxation of changes in properties' assessed values for a number of years (New York City Department of Finance, 2011; New York City Economic Development Corporation, 2012). The New York City Department of Finance provided us with longitudinal data on commercial and residential properties receiving 
tax exemptions for Fiscal Years (FY) 1984-2011. ${ }^{8}$ The living wage proposal included a minimum financial assistance threshold of $\$ 100,000$ for mandating living wages. However, it was not specified how to calculate the threshold (net present value, yearly assistance, etc.); the analysis was conducted based on buildings that received real property tax exemptions of $\$ 100,000$ or more in at least one fiscal year. ${ }^{9}$ The proposal also required that, once the threshold was met, the mandates would apply for the life of the financial assistance or 30 years, whichever was longer.

The information on properties receiving tax exemptions was matched to business establishments in the Quarterly Census of Employment and Wages (QCEW) data for 2006-2008 - confidential data provided to NYCEDC for the analysis. ${ }^{10}$ The QCEW has information on average quarterly earnings and number of jobs, by establishment, and on the address of each establishment, which was geocoded to real properties; ${ }^{11}$ we matched to sites that ever received assistance through FY 2011, to provide the most representative snapshot of what kinds of businesses locate in properties receiving financial assistance. We use the data to estimate the share of workers potentially affected by the living wage law and the increases in wages that would be experienced by affected workers, by borough and by industry. We use data on all forprofit employers at covered sites, since many non-profits were exempted from the proposed law.

We want to estimate how many of the workers at sites that received real property tax assistance at some point in the period FY 1984-FY 2011 (“covered sites") would be affected by the proposed living wage law, and by how much. However, because we have no information about the distribution of wages within a QCEW establishment, we have to estimate this wage distribution and hence the share of workers paid less than $\$ 10$ per hour. ${ }^{12}$ We first estimate the percentiles of the wage distribution by industry and borough of employment using the ACS. We cannot just assume that the ACS wage distribution holds equally at all establishments in the 
industry and borough, because wage levels may vary across employers. We therefore use the QCEW, for each industry and borough, to estimate the wage level for covered establishments. This, in turn, requires an estimate of average hours worked at establishments, because the QCEW counts positions (including part-time). We use the ACS data to estimate average hours by industry and borough of employment and apply this to the QCEW data, by industry and borough, to estimate average wages. Finally, we compute the percentage difference between the average ACS hourly wage and the average QCEW wage in the industry and borough, and then adjust the percentiles of the ACS wage distribution by this amount to arrive at an estimated wage distribution for employees at covered establishments in each industry and borough. ${ }^{13}$ We can then calculate the wage increases needed to bring wages up to $\$ 10$, and the implied average percentage wage increase for affected workers and for all workers. This calculation approximates the change in wages that would actually occur in New York City if those earning less than $\$ 10$ at covered sites were brought to that level.

Finally, we incorporated information on a wide range of income-support and other assistance programs that are provided through federal, state, and city resources to New York City residents. Many of these programs have eligibility requirements or determinants of benefit levels based on household characteristics that are not reported in the ACS data, and others provide benefits that cannot directly be measured in dollar terms (e.g., Home Energy Assistance Program and NYC Housing Authority Resident Employment Services). Thus, we limited our analysis to three larger programs - SNAP (formerly food stamps), the EITC (federal, state, and New York City's), and Medicaid - for which eligibility and benefit levels can be determined or estimated from the ACS data. SNAP and EITC benefits can be measured in dollar terms, whereas the dollar benefits of Medicaid depend on the family's usage of medical services. We therefore measure the effect of the proposed living wage in terms of dollars for the SNAP and EITC 
programs and in terms of participation for the Medicaid program. Because the ACS data do not provide detailed information on assistance program participation or with which to predict participation well, we assume all families that are eligible to participate in a particular program based on simulated family earnings do participate.

\section{Living Wage Coverage}

Our calculations of the percent of employees who would be subject to the living wage law, and the simulations that follow from them, are based on sites that received real property tax assistance of $\$ 100,000$ or more in at least one year. This threshold also happens to be fairly consistent with living wage laws in other locations, and hence the CPS estimates of the employment elasticity (and the other CPS estimates we which we compare some of our simulation results) are roughly speaking applicable to a definition of coverage based on this criterion. Based on workers employed at sites that received $\$ 100,000$ in assistance, the estimated percentage of workers earning less than $\$ 10$ per hour who would have been subject to the living wage laws ranges from $9.9 \%$ in Brooklyn to $31.3 \%$ in Staten Island, and is $12.9 \%$ across all boroughs. There is also considerable variation across industries, from $4 \%$ in construction to $24.4 \%$ in retail trade. The potential impact of the living wage legislation depends on the percentage of low-wage workers employed at sites receiving assistance, the number of low-wage workers in the industry, and wages in the industry.

\section{$\underline{\text { Simulation Methods }}$}

We begin with wages. The QCEW data provide estimates of the share of employment in each borough and industry at covered sites. For each borough ( $b$, based on place of work) and industry (i) we denote the share of workers earning less than $\$ 10$ per hour who are employed at sites that received assistance in that borough and industry as $C E_{b i}$, which is the number of workers earning less than $\$ 10$ per hour employed at sites receiving assistance in a borough and 
industry divided by the total number of workers earning less than $\$ 10$ per hour in the same borough and industry.

To simulate the effects of the living wage, we have to assign wage increases to some workers who earn less than $\$ 10$ per hour. In the ACS data, we can identify workers employed in any borough $b$ and industry $i$ who earn less than $\$ 10$ per hour. Using the estimates of $C E_{b i}$ from the QCEW data, we apply the living wage to the borough and industry using the following method. For all workers employed in borough $b$ and industry $i$, we take those who earn less than $\$ 10$ per hour and give them a wage of $\$ 10$ per hour with probability $C E_{b i}$, while leaving their wage unchanged with probability $\left(1-C E_{b i}\right)$. For those who are assigned the living wage rate, we assume no change in hours or weeks worked. For the purposes of calculating how the living wage would affect the wage distribution, this "random assignment" is better than just giving everyone the "expected" increase. Giving everyone the expected increase would lead to badly estimated distributional effects. This is particularly important when we examine whether a family is pushed above an income threshold, which can be very different depending on how the benefits are distributed.

Some individuals in the ACS data have wages below the minimum wage (either due to measurement error, non-compliance with local minimum wage laws, or inapplicability of the minimum wage). We assume most individuals who would be subject to the law have an hourly pay rate at or above the minimum wage, and therefore in the simulations restrict the population eligible for a wage increase to those who report a wage that is at or above the 2006 minimum wage that is applicable to New York City workers $-\$ 6.75$ per hour. ${ }^{14}$ These restrictions also reduce measurement error from individuals reporting unusual hours, earnings, and weeks worked in the ACS. We also exclude self-employed earners.

The ACS data are reported at the individual level, but the individuals are representative 
individuals with specific weights based on the number of actual persons in New York City that they represent. In order to apply wage changes randomly to individuals working in New York City, we expand the ACS data by creating duplicate records for each individual based on their household weight. Using this expanded file, we randomly assign the living wage to individuals earning less than $\$ 10$ per hour by borough and industry based on the above method. The household weight was used so that we could aggregate individuals back to a complete household level (each person in the household receives the same household weight).

The QCEW data capture those who work in New York City without regard to where they live. However, the ACS data capture place of residence and place of work. Since we are primarily interested in the effects on residents of New York City, we report the wage and employment effects for New York City residents. Nonetheless, some of the effects of the living wage would fall on residents of other cities and states who work in New York City. Below, these "outflows" are reported separately from the results pertaining to New York City residents and are labeled "Outside New York City."

Given that our estimates from the CPS data indicate some probability of job loss, we also assign job loss to simulate the effects of the proposed living wage law. We tie our projected employment effects explicitly to the CPS evidence, using the elasticity of -0.055 discussed earlier, although we do not do this for wages because the CPS results on wages were less precise, and for New York City the QCEW and ACS data enable us to estimate the wage distribution at affected firms - something that could not be done with the CPS data. This reflects the tradeoffs between relying on longitudinal studies of other cities versus ex ante simulations; with regard to wages, we have more specific information about likely effects on wages in New York City, and hence use that information.

For most boroughs and industries, a $\$ 10$ per hour living wage rate is above the $10^{\text {th }}$ 
percentile of the wage distribution, implying that the estimated CPS employment effects would apply only to workers earning less than the living wage. However, we assume that our CPS employment elasticity to mandated wage increases above the minimum wage for the lower decile would approximately fall on the workers who, according to the QCEW data, would have their wages affected by the living wage, hence applying the earlier estimates for workers in each borough and industry that have wages below $\$ 10 .^{15}$

We calculate the predicted decline in employment among those workers earning below $\$ 10$ per hour, given the proposed living wage increase and the estimated employment elasticity. This yields, overall for the city, a predicted probability of job loss, denoted $p$. We use the -0.055 employment elasticity described earlier. This elasticity comes from the longitudinal evidence from other cities, and estimates the effect of increasing the living wage conditional on the other controls in the regression model. It therefore provides an estimate of what would happen in a single city where, as mimicked by the regression model, everything else (including possible underlying trends) remains the same. Applying this elasticity to the increase in the wage floor from the New York state minimum wage of $\$ 6.75$ to the $\$ 10$ living wage that the law would entail, a $48.1 \%$ increase implies an employment decline of $2.65 \%(0.055 \times 0.481 \times 100)$ among those earning less than $\$ 10$ per hour.

The job loss presumably occurs among those at covered sites, although we simply apply this to workers in the ACS earning less than $\$ 10$ per hour - distributed by industry and borough based on their estimated wage distributions - because we cannot identify which workers in the ACS work at covered sites. For each industry and borough we have an estimate of the share of workers earning less than $\$ 10$ per hour working at covered sites $\left(C E_{b i}\right)$. We want to assign job loss with higher probability to those who are more likely to be working at a covered site, based on their industry and borough of employment. To do this, we construct the probability that a 
worker earning less than $\$ 10$ per hour working in borough $b$ and industry $i$ is at a covered site relative to the probability that any worker earning less than $\$ 10$ per hour working in the city is at a covered site $\left(C E_{\text {city }}\right)$. We then use a probability of job loss for a worker earning less than $\$ 10$ per hour in borough $b$ and industry $i$ of $p \times\left\{C E_{b i} / C E_{c i t y}\right\}$.

The simulations give us new wages for some workers and different employment statuses for others. Using these wage and employment changes for individuals, we simulate the effects of the living wage law on families by calculating how the distribution of family income changes, in particular relative to the poverty line and one-half the poverty line ("extreme poverty"), using the poverty threshold for New York City from the New York Center for Economic Opportunity (2011); we refer to these as "CEO thresholds."16 One limitation of this kind of simulation study of the effects of the living wage on family incomes is that we do not know the actual distribution of those who get wage gains and those who lose jobs across families with different levels of income (or differences in other characteristics). In contrast, we simulate effects assuming that these gains and losses from living wages are randomly distributed across potentially affected workers in proportion to their representation in the data by industry and borough. ${ }^{17}$

The living wage proposal we studied would apply to new recipients of financial assistance and to existing recipients in case of renewal or amendment of the original agreements. We do not know when or if current sites receiving financial assistance would, in the future, be new recipients as a result of assistance renewal, or when new developments will qualify for and receive assistance in the future. As a consequence, we know of no reliable way to, for example, isolate some sites that would be recipients of new financial assistance in the next year, the next two years, etc. Instead, we assume the effects apply to all covered workers. As a result, the results should be thought of as long-run effects. Given that most other cities also apply business assistance provisions of living wage laws to new projects only, and have been implemented at 
different times, it is likely that the estimates from the CPS data that we use for the employment response is intermediate between short-run or long-run effects.

\section{$\underline{\text { Wage and Employment Effects }}$}

The dark bars in Figure 1 show the baseline wage distribution (up to \$13.50) for those living and working in New York City. The vertical distance measures the percentage in each range relative to all workers living and working in the city. The chart includes all those with positive wages, but in our simulation only those earning between $\$ 6.75$ and $\$ 10.00$ could have their wages changed by the living wage. The second set of bars (labeled "Implementation of Living Wage") shows the wage distribution after simulating the wage effects, with no employment effects. This bar is below each of the baseline bars less than $\$ 10$ and then spikes at $\$ 10$, with no changes above the proposed living wage, because those who are assigned wage changes have their wages increased to $\$ 10$. The last and lightest bars show the distribution of individuals after simulating the employment effects as well, where those who become disemployed are assigned a wage of zero. In each instance the third bar is slightly below the second bar for wages of $\$ 10$ or less, and these reductions cumulatively add to the small mass in the $\$ 0$ wage column, reflecting job loss.

[Figure 1 about here]

To provide some information on the variation in these effects across boroughs, and in an industry that would likely be strongly affected, Figure 2 reports results for retail by borough. The figure is limited to those who either received a wage increase (to $\$ 10$ ) or experienced a job loss. The largest impacts appear in Staten Island and the smallest impacts in Manhattan. And of course the impacts are bigger than those in Figure 1. ${ }^{18}$

[Figure 2 about here]

Table 1 provides more information on these wage and employment effects. Looking 
citywide, the table shows that about $13 \%$ of the workforce at covered sites are estimated to earn less than $\$ 10$ per hour, and hence would have their wage increased by the living wage. Our estimates indicate that roughly 33,600 workers would receive wage increases. The average increase for those who receive the living wage is substantial $(\$ 1.67) .{ }^{19}$ Our simulations imply that just fewer than 6,000 would lose their jobs.

Relative to the entire workforce, the proposed living wage would impact a little more than $1.2 \%$ of the entire workforce. But this percentage is more than twice as high in the Bronx $(1.6 \%)$ than in Manhattan $(0.7 \%)$, owing to differences in both industry composition and wage levels. The living wage would have a small impact on average wages of the entire workforce ( $0.1 \%$ increase), and on overall employment (a $0.2 \%$ decrease). These effects vary in a similar way by borough. Finally, we see that some (approximately $8 \%$ ) of those receiving the benefit of the living wage mandate reside outside of New York City, suggesting that "leakage" to nonresidents is not very large.

[Table 1 about here]

\section{Effects on Poverty and Family Income}

Table 2 reports on the results of the simulation for whether families are moved over the thresholds for poverty or extreme poverty. The first column reports the baseline percentages of families in extreme poverty (top panel) or poverty (bottom panel) for the city overall and each of the boroughs, and the second column shows the percentages after we simulate the effects of living wages, assigning the wage increases and employment losses reported in the previous table. A comparison of these columns shows that the simulated changes in the income distribution in terms of these two thresholds are small, and they are mixed in terms of direction. As the top panel of the table shows, overall the percentage of all families classified as "extreme poor" would slightly increase, by 0.05 percentage point, or $0.5 \%$; this would certainly be viewed as an 
unintended adverse consequence of the living wage. However, as the bottom panel shows, the percent of families below poverty would slightly decrease by 0.02 percentage points, or $0.08 \%$.

The numbers of affected families are correspondingly fairly small. The simulations indicate that an additional 1,200 families would enter extreme poverty, while about 400 families would be lifted out of poverty. In other words, some families below the poverty line would be lifted above it, while others below the poverty line would sink further beneath it, in what is a rather stark illustration of the fact that a higher living wage, given disemployment effects, creates both winners - those who get higher wages - and losers - those who lose their jobs. Overall, the results show that while the number of workers receiving wage increases is considerably higher than the number of workers experiencing job losses, the aggregate effect on the distribution of income is negligible. In other words, the simulations suggest that the living wage mandate would mainly redistribute income from some low-skill workers who lose jobs to other low-skill workers who earn higher wages.

These simulated impacts on poverty are lower than those experienced on average for other cities imposing living wage laws, as discussed above with respect to the CPS estimates. However, the findings are not inconsistent. The poverty thresholds used in the simulations are those reported by the New York City Center for Economic Opportunity (2011), which are higher than the federally poverty thresholds used in the CPS estimates. In addition, when we redid the the simulations without restricting affected workers to those earning at least the 2006 minimum wage rate, the impacts on poverty look more comparable to those estimated using the CPS data, even when we apply the NYC CEO poverty thresholds.

[Table 2 about here]

\section{$\underline{\text { Income-Support and Other Programs }}$}

Given that many income-support programs require low family income to qualify, or tie 
benefits to income, we might expect the beneficial effects of living wages to be more limited than the increase in earnings, because rising earnings reduce eligibility for benefits or affect the amounts for which workers are eligible from social programs such as Medicaid, S-CHIP, Food Stamps, housing assistance, and the Earned Income Tax Credit decline. The implication is that families that see earnings rise because of a living wage law would also receive fewer government benefits. Of course, the effects of job loss go in the opposite direction.

These changes might be of interest to local policymakers. If benefits decline, then to the extent that these benefits come from the federal (or state) government, there would be less money coming into a city. As a prime example, the federal Earned Income Tax Credit (EITC) has grown into the largest program for providing income support to lower-income families (Blank, 2002). As a consequence, when a worker's earnings rise, the inflow of federal dollars via the EITC can decline. On the other hand, the expenses for some benefits paid by the local government would fall.

Our simulation goes into more detail on how the proposed living wage law would affect local, state, and federal expenditures on income-support and other programs in New York City. Program participation and benefit levels are estimated based on the current rules and award levels. The specific eligibility guidelines and charts showing benefit levels were obtained through state and federal government websites providing program details. ${ }^{20}$ Medicaid and EITC eligibility and benefits are determined based on family income and number of family members. SNAP eligibility and benefits were also determined based on family size and income and applied the standard household and shelter deductions. Estimated EITC eligibility and benefit levels are based solely on family income, family size, and family structure (age of family members), and implicitly assume families pass the other eligibility requirements for which we have no data. We calculate family eligibility and benefit levels prior to assigning wage and employment effects, 
and then after assigning the simulated effects that we project would result from the living wage law, to determine how assistance would be impacted.

For Medicaid and SNAP, there is a clear predicted relationship whereby eligibility or benefits decrease as earnings increase. However, for the EITC, benefits initially rise as earnings increase over some range, then remain flat, and eventually decrease. So, for families affected by the living wage EITC benefits may decline or increase depending on family income and the effects of the living wage.

Table 3 shows the aggregate impacts on eligibility and potential benefit levels for New York City families when the effects of the proposed living wage are simulated. The simulations show declines in EITC payments, and in eligibility for and benefits from SNAP, but an increase in the percentage eligible for Medicaid. ${ }^{21}$ The changes range from approximately a $0.5 \%$ decrease to a $0.2 \%$ increase. Not surprisingly, boroughs with a higher percentage of low-wage workers covered (e.g., Staten Island) are projected to experience greater changes in eligibility and benefit levels, and boroughs with a lower percentage of low-wage workers covered (e.g., Manhattan) are expected to have smaller changes. With respect to the EITC and SNAP, these conclusions imply that where a living wage law has the potential to deliver the most benefit because wages are lower, the earnings gains are likely to be more strongly offset because of declines in income from or eligibility for government assistance.

[Table 3 about here]

Finally, Table 3 also reports the changes in aggregate earnings and benefit amounts that are implied by simulating the impact of the living wage. Based on the simulated effects, family earnings would increase by approximately $\$ 11.6$ million. Referring back to Table 2 , these increases come from the approximately 34,000 workers who experience a wage increase, while approximately 6,000 workers experience reduced earnings due to disemployment. SNAP 
benefits decline only slightly, while EITC benefits would decline by approximately $\$ 4.6$ million, offsetting over one third of the income gains.

\section{Conclusions}

We project the effects of a prospective living wage law in New York City, a type of exercise that has been fairly common in recent years and shares many features with prospective evaluations of other proposed policies. Longitudinal estimation of living wages implemented in some cities can be used to estimate effects based on historical experience, but may fail to capture unique features of a specific labor market or policy proposal. Nonetheless, ex ante simulations require some evidence from this historical experience to obtain magnitudes of behavioral responses used in the simulations. We therefore combine the two methods. In addition, newlyavailable administrative data on the labor market and covered employers, as well as detailed information on where people live and work in the ACS, increase the scope for basing these kinds of studies on a very accurate and complete empirical description of the relevant labor market. This paper demonstrates how we use these methods and data to study the proposed living wage law, and argues that these kinds of prospective evaluations should use these mixed methods and new data sources.

The key point of the paper is its demonstration of methods and uses of data, rather than the specific conclusions, both because research on the actual effects of laws is ultimately how social science evaluates policy, and because the actual law implemented could end up differing from the one we studied, as it in fact did (as discussed below). For the record, nonetheless, the longitudinal evidence points to living wages generating both winners and losers - the former those who get higher wages, and the latter those who become jobless. This evidence to some extent updates earlier research, although changes in geographic classifications in the CPS data pose challenges in updating the evidence to the present. 
These estimated wage and employment effects, along with the administrative and ACS data, are used in the simulations for New York City, in large part to assess the likely distributional effects of the proposed living wage. The predicted distributional effects are quite modest, with poverty or extreme poverty rates changing little - although the extreme poverty rate actually increases. Thus, the results suggest that the effect of living wages is primarily to shift earnings from some low-wage, low-skill workers to others. There is a net earnings gain to affected workers, but a sizable share of it (more than one-third) would likely be offset by lower EITC benefits.

Insofar as this paper is intended to outline how the effects of proposed living wage laws can be simulated, the methods, in our view, can be extended to other legislative proposals, while considerable caution should be exercised in generalizing the conclusions. The methods we have used take very explicit account of the likely effects of an actual living wage law, specifically by incorporating both the historical data on covered employers, and the administrative labor market data on workers' earnings at covered employers. These are very rich data, but once analysts have them in hand, a similar type of analysis can be done for other cities. Of course the ability of analysts to get access to these data - especially the establishment-level QCEW - may be limited, and may be less likely to be granted in small cities. And we should point out that only one member of our research team employed by the NYC Economic Development Corporation was able to work with these data directly; outside researchers working in isolation would face greater challenges.

The ACS data, in contrast, are publicly available, and can therefore be used for many other cities. However, for considerably smaller cities these data become less useful. The geographic designation in the ACS that identifies cities is the Public Use Microdata Area (PUMA). PUMAs are areas within a state with at least 100,000 residents. But they are generally 
constructed using counties as building blocks. ${ }^{22}$ Thus, for smaller cities that have larger portions of the counties they occupy outside city boundaries, the identification of city residents or workers is not as clean.

Generalizability of results is much trickier. First, the actual measurement of the number of affected firms, and the number and earnings of workers at those affected firms, can be quite different across cities. This depends on both the economic structure and economic conditions in different cities, and the structure of any proposed living wage law. We are of course aware that the economic structure of New York City is unique. New York City's proposed law is what we have termed a business assistance living wage mandate. Thus, the results are more generalizable to other laws that would cover recipients of assistance from cities. In contrast, expected results for the type of narrower contractor-only law would probably be quite different (and, based on the work in Adams and Neumark, 2005b, much more modest).

It is true that the legislative proposal that we studied would have been among the most aggressive business assistance living wage laws in the nation, in part because of the extensive proposed coverage, and in part because of steep penalties for non-compliance. ${ }^{23}$ In particular, the living wage ordinance proposed for New York City differed from that in other cities in terms of its transference of liability to developers, landlords, or owners of the building, as they are the financial assistance "recipients," rather than the normal practice of placing liability primarily on employers only. However, this feature of the living wage law did not really enter into our labor market calculations, as the employment elasticity - which is a key driver of the simulations was based on evidence from other cities. Thus, the results may be somewhat generalizable, and hence provide a benchmark, for business assistance living wage laws in other cities where the living wage falls at a similar percentile of the wage distribution at covered sites and there is a similar share of workers covered by the law - at least for large cities that share some features 
with New York City.

Indeed, given these features of the proposed living wage law, it is likely that because this key elasticity comes from other cities, we have understated the effects of the proposed law in New York City. Moreover, the larger report (Charles River Associates, 2011), of which our labor market research was one component, also studied how the real estate market in New York City was likely to be affected by the proposed living wage law. The real estate analysis suggested potentially quite adverse effects on real estate development in New York City owing to the coverage of the living wage law, who liability would have been extended to, and the penalties for non-compliance, which include repayment of the financial assistance received. Because labor markets and real estate markets are closely related, were these adverse effects on real estate development to occur, the labor market impacts could be worse than the relatively modest impacts suggested by our labor market analysis.

Finally, by way of emphasizing that any simulation exercise like the one we present in this paper must be attuned to the details of the specific living wage law under consideration, it turns out that New York City ended up adopting a considerably weaker living wage law (Local Law 37, in June, 2012). ${ }^{24}$ This law reduces coverage in a number of ways. It applies only to recipients of "discretionary" assistance rather than the broader category in the proposed law we were asked to study, which included "as-of-right" assistance recipients. It exempted tenants and sub-tenants of recipients of assistance, unless they have a majority stake, and also exempted nonprofits (largely exempted as well under the original proposal), manufacturing firms, some other affordable housing, retail, and commercial development projects, and business with annual gross revenues less than $\$ 5$ million. Finally, it raised the threshold for coverage to at least $\$ 1$ million of assistance in present value. The estimates presented in our paper are based on a much larger employment base that included nearly all of the now-exempted businesses. There is little doubt 
then, that the far narrower coverage of Local Law 37 would imply much smaller effects than those we report in this paper. Nonetheless, the methods we use could be readily applied to simulate the effects of the new law, using the data sources we have brought to bear on the problem that allow identification of covered employers and which permit estimation of the distribution of earnings at those employers. 


\section{References}

Adams, S., \& Neumark, D. (2005a). When do living wages bite? Industrial Relations, 44(1), 164-192.

Adams, S., \& Neumark, D. (2005b). Living wage effects: New and improved evidence. Economic Development Quarterly, 19(1), 80-102.

Blank, R. M. (2002). Evaluating welfare reform in the United States. Journal of Economic Literature, 40(4), 1105-1166.

Charles River Associates. (2011). The economic impacts on New York City of the proposed living wage mandate. Retrieved December 13, 2011, from http://www.nycedc.com/NewsPublications/Studies/Documents/CombinedReportLivingWageImp acts.pdf.

Citro, Constance F. and Robert T. Michael, eds. (1995). Measuring poverty: A new approach. Washington, DC: National Academy Press, 1995

Groshen, E. L. (1991). The structure of the female/male wage differential: Is it who you are, what you do, or where you work? Journal of Human Resources, 26(3), 457-472.

Holzer, H. J. (2008). Living wage laws: How much do (can) they matter? Discussion Paper, Brookings Institution Metropolitan Policy Program, Washington, DC, December.

Neumark, D., \& Adams, S. 2003. Do living wage ordinances help reduce urban poverty? 38(3), 490-521.

Neumark, D., Schweitzer, M., \& Wascher, W. (2005). The effects of minimum wages on the distribution of family incomes: A nonparametric analysis. Journal of Human Resources, 40(4), 867-894.

Neumark, D., Thompson, M., Brindisi, F., Koyle, L., \& Reck, C. (2012). Estimating the economic impacts of living wage mandates using ex ante simulations, longitudinal estimates, and 
new public and administrative data: Evidence for New York City. Working Paper No. 18055. Cambridge, MA: National Bureau of Economic Research.

New York Center for Economic Opportunity. (2011). Policy affects poverty: The CEO poverty measure, 2005-2009. Retrieved September 29, 2012, from http://www.nyc.gov/html/ceo/downloads/pdf/poverty_measure_2011.pdf.

New York City Department of Finance. (2011, February). Annual report on tax expenditures fiscal year 2011. Retrieved February 15, 2012, from http://www.nyc.gov/html/dof/html/pdf/11pdf/ter_2011_final.pdf.

New York City Economic Development Corporation. (2012, January). Annual investment projects report fiscal year 2011. Retrieved February 15, 2012, from http://www.nycedc.com/about-nycedc/financial-public-documents.

Pollin, R., \& Luce, S. (1998). The living wage: Building a fair economy. New York: The New Press. 
Figure 1: Distribution of Wages Before and After Implementation of a \$10 Living Wage Law (based on sites receiving $\mathbf{\$ 1 0 0 , 0 0 0}$ or more of assistance in at least one year)

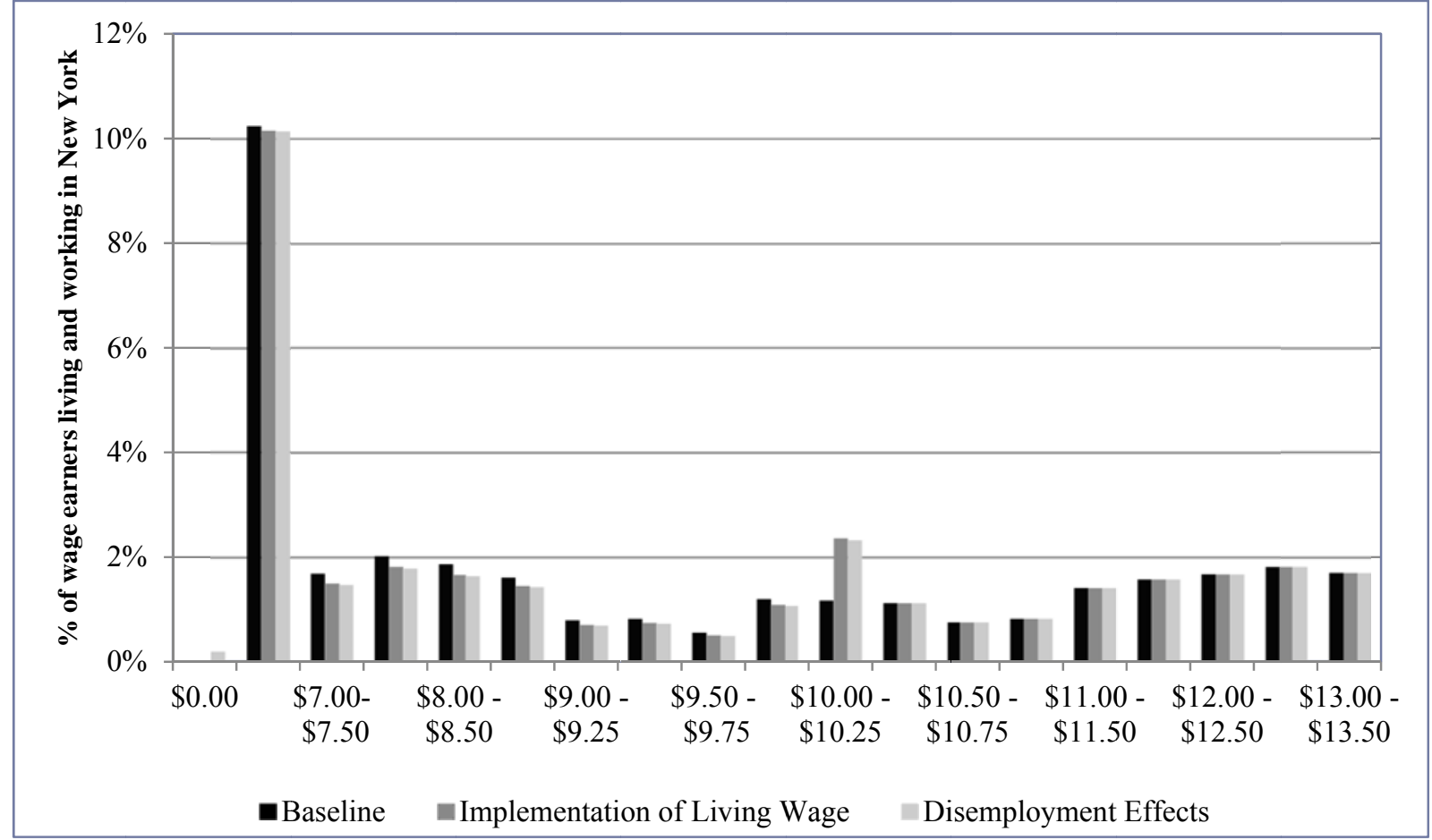

Source: Authors' simulations. 
Figure 2: Distribution of Wages Before and After Implementation of a \$10 Living Wage Law, Retail Trade Industry, by Borough (based on sites receiving $\mathbf{\$ 1 0 0 , 0 0 0}$ or more of assistance in at least one year)

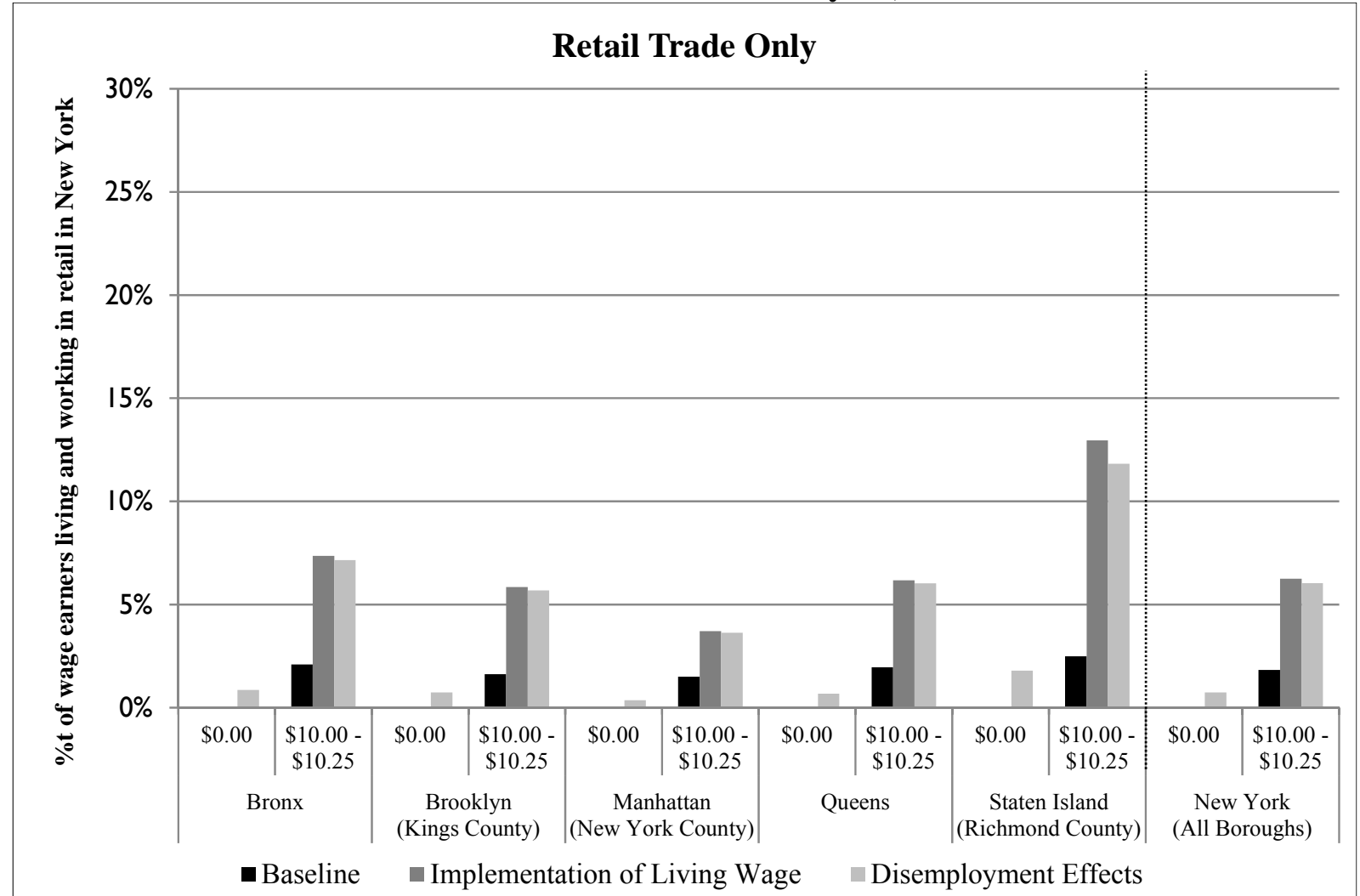

Source: Authors' simulations. 
Table 1: Wage and Employment Changes, Overall, by Borough, and Outside New York City (based on sites receiving $\mathbf{\$ 1 0 0 , 0 0 0}$ or more of assistance in at least one year)

\begin{tabular}{|c|c|c|c|c|c|c|c|}
\hline & $\begin{array}{c}\text { \% of workers earning } \\
\text { < } \$ 10 \text { per hour } \\
\text { employed at covered } \\
\text { sites ("affected") }\end{array}$ & $\begin{array}{c}\text { Number of } \\
\text { affected } \\
\text { workers with } \\
\text { wage increases }\end{array}$ & $\begin{array}{c}\text { Average wage } \\
\text { increase, affected } \\
\text { workers who get } \\
\text { wage increase }\end{array}$ & $\begin{array}{c}\text { Number of } \\
\text { affected } \\
\text { workers } \\
\text { losing jobs }\end{array}$ & $\begin{array}{l}\% \text { affected } \\
\text { relative to } \\
\text { entire } \\
\text { workforce }\end{array}$ & $\begin{array}{c}\text { Average } \% \\
\text { wage increase, } \\
\text { entire } \\
\text { workforce }\end{array}$ & $\begin{array}{l}\text { \% of entire } \\
\text { workforce } \\
\text { losing jobs }\end{array}$ \\
\hline New York City & $12.9 \%$ & 33,561 & $\$ 1.67$ & 5,896 & $1.2 \%$ & $0.1 \%$ & $0.2 \%$ \\
\hline Bronx & $12.9 \%$ & 6,017 & $\$ 1.70$ & 1,067 & $1.6 \%$ & $0.1 \%$ & $0.3 \%$ \\
\hline Brooklyn & $9.9 \%$ & 9,749 & $\$ 1.64$ & 1,734 & $1.1 \%$ & $0.1 \%$ & $0.2 \%$ \\
\hline Manhattan & $12.5 \%$ & 4,437 & $\$ 1.68$ & 778 & $0.7 \%$ & $0.0 \%$ & $0.1 \%$ \\
\hline Queens & $13.5 \%$ & 10,815 & $\$ 1.66$ & 1,845 & $1.4 \%$ & $0.1 \%$ & $0.2 \%$ \\
\hline Staten Island & $31.3 \%$ & 2,543 & $\$ 1.65$ & 472 & $1.5 \%$ & $0.1 \%$ & $0.3 \%$ \\
\hline $\begin{array}{l}\text { Outside New York } \\
\text { City }\end{array}$ & & 2,820 & $\$ 1.50$ & 490 & & & \\
\hline
\end{tabular}

Source: Authors' simulations. 
Table 2: Changes in Family Poverty Status, by Borough (based on sites receiving $\$ 100,000$ or more of assistance in at least one year, and CEO poverty thresholds)

\begin{tabular}{|c|c|c|c|c|c|c|c|}
\hline & $\begin{array}{l}\% \text { of all } \\
\text { families, } \\
\text { baseline }\end{array}$ & $\begin{array}{l}\% \text { of families, } \\
\text { after living wage } \\
\text { implemented }\end{array}$ & $\begin{array}{c}\text { Percentage } \\
\text { point } \\
\text { difference }\end{array}$ & $\begin{array}{c}\% \\
\text { change }\end{array}$ & $\begin{array}{c}\text { Families, } \\
\text { baseline }\end{array}$ & $\begin{array}{c}\text { Families, } \\
\text { after living } \\
\text { wage } \\
\text { implemented }\end{array}$ & $\begin{array}{c}\text { Change in } \\
\text { number of } \\
\text { families }\end{array}$ \\
\hline \multicolumn{8}{|c|}{ Families in extreme poverty } \\
\hline New York City & $9.55 \%$ & $9.60 \%$ & $0.05 \%$ & $0.50 \%$ & 245,600 & 246,816 & 1,216 \\
\hline Bronx & $14.27 \%$ & $14.32 \%$ & $0.05 \%$ & $0.34 \%$ & 54,170 & 54,352 & 182 \\
\hline Brooklyn & $9.28 \%$ & $9.34 \%$ & $0.05 \%$ & $0.59 \%$ & 66,858 & 67,252 & 394 \\
\hline Manhattan & $10.03 \%$ & $10.07 \%$ & $0.03 \%$ & $0.32 \%$ & 65,182 & 65,388 & 206 \\
\hline Queens & $7.17 \%$ & $7.24 \%$ & $0.07 \%$ & $0.99 \%$ & 48,764 & 49,248 & 484 \\
\hline Staten Island & $7.51 \%$ & $7.47 \%$ & $-0.04 \%$ & $-0.47 \%$ & 10,626 & 10,576 & -50 \\
\hline \multicolumn{8}{|c|}{ Families below poverty } \\
\hline New York City & $20.70 \%$ & $20.69 \%$ & $-0.02 \%$ & $-0.08 \%$ & 532,333 & 531,910 & -423 \\
\hline Bronx & $29.49 \%$ & $29.48 \%$ & $-0.01 \%$ & $-0.02 \%$ & 111,923 & 111,896 & -27 \\
\hline Brooklyn & $22.07 \%$ & $22.06 \%$ & $-0.01 \%$ & $-0.05 \%$ & 158,980 & 158,899 & -81 \\
\hline Manhattan & $17.78 \%$ & $17.76 \%$ & $-0.02 \%$ & $-0.09 \%$ & 115,466 & 115,360 & -106 \\
\hline Queens & $18.21 \%$ & $18.19 \%$ & $-0.02 \%$ & $-0.09 \%$ & 123,864 & 123,753 & -111 \\
\hline Staten Island & $15.62 \%$ & $15.55 \%$ & $-0.07 \%$ & $-0.44 \%$ & 22,100 & 22,002 & -98 \\
\hline
\end{tabular}

Source: Authors' simulations. 
Table 3: Changes in Support Programs

(based on sites receiving $\$ \mathbf{1 0 0 , 0 0 0}$ or more of assistance in at least one year)

\begin{tabular}{|c|c|c|c|c|c|}
\hline & & $\begin{array}{l}\text { Percent } \\
\text { change in } \\
\text { EITC } \\
\text { amount }\end{array}$ & $\begin{array}{l}\text { Percent } \\
\text { change in } \\
\text { number } \\
\text { Medicaid } \\
\text { eligible }\end{array}$ & $\begin{array}{c}\text { Percent } \\
\text { change in } \\
\text { number } \\
\text { SNAP } \\
\text { eligible }\end{array}$ & $\begin{array}{c}\text { Percent } \\
\text { change in } \\
\text { total } \\
\text { amount of } \\
\text { SNAP }\end{array}$ \\
\hline New York City & & $-0.45 \%$ & $0.21 \%$ & $-0.18 \%$ & $-0.11 \%$ \\
\hline Bronx & & $-0.49 \%$ & $0.12 \%$ & $-0.11 \%$ & $-0.07 \%$ \\
\hline Brooklyn (Kings County) & & $-0.44 \%$ & $0.20 \%$ & $-0.16 \%$ & $-0.10 \%$ \\
\hline Manhattan (New York County) & & $-0.45 \%$ & $0.16 \%$ & $-0.12 \%$ & $-0.08 \%$ \\
\hline Queens & & $-0.47 \%$ & $0.39 \%$ & $-0.29 \%$ & $-0.16 \%$ \\
\hline \multirow[t]{2}{*}{ Staten Island (Richmond County) } & & $-0.28 \%$ & $0.06 \%$ & $-0.45 \%$ & $-0.14 \%$ \\
\hline & $\begin{array}{c}\text { Change in } \\
\text { total } \\
\text { earnings }\end{array}$ & $\begin{array}{c}\text { Change in } \\
\text { EITC } \\
\text { amount }\end{array}$ & $\begin{array}{l}\text { Change in } \\
\text { number } \\
\text { Medicaid } \\
\text { eligible }\end{array}$ & $\begin{array}{c}\text { Change in } \\
\text { number } \\
\text { SNAP } \\
\text { eligible }\end{array}$ & $\begin{array}{c}\text { Change in } \\
\text { total } \\
\text { amount of } \\
\text { SNAP }\end{array}$ \\
\hline New York City & $\$ 11,614,097$ & $-\$ 4,639,732$ & 784 & -945 & $-\$ 198,478$ \\
\hline Bronx & $\$ 2,525,020$ & $-\$ 1,196,001$ & 100 & -114 & $-\$ 27,741$ \\
\hline Brooklyn (Kings County) & $\$ 2,818,007$ & $-\$ 1,517,036$ & 226 & -249 & $-\$ 63,228$ \\
\hline New York (Manhattan) & $\$ 1,567,378$ & $-\$ 613,921$ & 132 & -140 & $-\$ 28,573$ \\
\hline Queens & $\$ 4,679,903$ & $-\$ 1,204,460$ & 316 & -346 & $-\$ 68,554$ \\
\hline Staten Island (Richmond County) & $\$ 23,789$ & $-\$ 108,314$ & 10 & -96 & $-\$ 10,383$ \\
\hline
\end{tabular}

Source: Authors' simulations. 


\section{Endnotes}

${ }^{1}$ See http://legistar.council.nyc.gov/LegislationDetail.aspx?ID=664291\&GUID=A83A5A5B9589-4589-AAD7-5B2C6884610F\&Options=ID $\mid$ Text $\mid \&$ Search=251 (viewed November 2, 2011).

${ }^{2}$ For example, see http://nelp.3cdn.net/67dcccd3fc93450105_14m6ibn7g.pdf (viewed December $13,2011)$.

${ }^{3}$ For a relatively recent review of research on living wages prior to our study see Holzer (2008).

${ }^{4}$ We would argue that the detailed data and information we use would also enable better beforeand-after studies, and that they could be used in the evaluation of other labor market policies.

${ }^{5}$ Our analysis sample includes 79 MSAs/PMSAs, in which 23 major cities had living wage laws. Some cities passed laws that were never implemented, for instance because of a subsequent court decisions (see Adams and Neumark, 2005a). Only living wage laws that were actually implemented are included.

${ }^{6}$ We collected extensive information on other characteristics of living wage laws, with the goal of estimating effects of particular living wage laws most similar to the one proposed for New York City. However, as detailed in Charles River Associates (2011), no city had the panoply of penalties and costs proposed for New York City, including putting the burden of monitoring costs on the developer or owner of a building, or repayment of subsidies for violations. More generally, it turned out to be fruitless to estimate the effects of other features of living wage laws that have parallels to the proposed law in New York City, because there simply are not that many cities with living wage laws, and once we look for specific features of the laws, there is at most a handful of them. To some extent, this parallels the findings from Adams and Neumark (2005a) that were unable to pin down strong evidence of differences in effects of different types of living wage laws. As a consequence, the longitudinal analysis could not be used to learn about the 
experiences of other cities with living wages very similar to that proposed for New York City; rather, the best we could do was to focus on business assistance living wage laws. This problem highlights why ex ante simulations that capture the unique features of a city's law are important. ${ }^{7}$ As noted earlier, there is some debate about these findings. Holzer's (2008) review can perhaps be viewed as providing a "third-party" view of the original Neumark and Adams studies, as well as of the criticisms of these studies and of city-specific studies of the effects of living wages by other authors. Regarding the criticisms, Holzer concludes, "Though I find their [Neumark and Adams'] arguments more compelling than those of their critics on many of these issues, some concerns over sample sizes and representativeness both within and across their cities remain" (p. 17, brackets added). Regarding the larger set of studies, Holzer concludes that "[T]here is some consensus across most of them that wages rise among the least-paid workers, while their employment levels modestly decline (at the covered firms and maybe more broadly), as a result of these laws" (p. 20).

${ }^{8}$ New York City fiscal years run from July 1 of a calendar year to June 30 of the following year, and are referenced by the calendar year on June 30. Based on the proposed legislation, the types of exemptions considered were: Industrial and Commercial Incentive Program (ICIP), 421-a, NYC Industrial Development Agency, and NYC Economic Development Corporation.

${ }^{9}$ There are relatively few investments entering the real estate exemption programs after FY 2008 because of the economic downturn. Furthermore, employment concentrates in commercial properties and the largest program for commercial properties (ICIP) was reformed and only applications submitted by the end of FY 2008 could qualify for it. ICIP was replaced by the Industrial and Commercial Abatement Program (ICAP) but our data do not contain information on abatements. 
${ }^{10}$ There are confidentiality restrictions on the QCEW data. The analysis reported here was based on aggregated information satisfying the following two restrictions: each industry-borough cell includes no less than three employers; and each employer accounts for less than $80 \%$ of the total. In the case of single-establishment employers, the QCEW data always refer to that establishment. For multi-establishment firms, the data reported by the employer are generally broken out by establishment. We always use the data at the establishment level except when we know the firm has multiple establishments but the data are not reported by establishment, in which case we treat the firm as an establishment and assign employment to the address reported in the QCEW.

${ }^{11}$ Because the geocoding is time intensive, we only geocoded data for one quarter from each of the three years covered by the ACS data, and then matched the data for this quarter to the QCEW data for other quarters and averaged employment and earnings over the calendar year. We used data from the third quarter because the data indicated a disproportionate share of births in the first quarter of the year and a disproportionate share of deaths in the fourth quarter.

12 The $\$ 10$ per hour floor is wage rate in the proposed living wage legislation when health benefits are provided by the employer. We use this rate in the simulations to be consistent with the estimates using the CPS data - both the earlier estimates and the updated estimates described briefly in this paper. If we were to assume that health benefits were not provided, the hourly rate associated with the proposed living wage law would increase to $\$ 11.50$ per hour, which, on its own, would imply somewhat larger effects.

${ }^{13} \mathrm{We}$ do the adjustment proportionally to avoid getting negative adjusted wage percentiles. The proportional adjustment parallels the standard wage equation specifications in the labor economics literature in which log wages are regressed on industry, occupation, or - when 
available - establishment dummy variables (e.g., Groshen, 1991). Our original intention was to do this establishment by establishment. However, it turned out that the average establishment wages in the QCEW data estimated this way have lots of outliers in both the positive and negative direction (i.e., very high and very low estimated hourly wages), which would have implied massive numbers of workers affected by the proposed living wage. The reason measurement errors of this type creates bias is because the artificially low wages that are estimated are not "offset" by the artificially high wages that are also estimated because it is only the artificially low wages that contribute to estimating wages that are below $\$ 10$ per hour. That is, the measurement error puts too many observations in both the lower and upper tails of the wage distribution, but it is only the former that matter. We are quite sure that the outliers are generated by the inapplicability of the average hours estimate to the specific establishments. If the hours estimate is too high, then the estimated hourly wage will be too low and vice versa. ${ }^{14}$ The applicable minimum wage is $\$ 6.75$ in 2006 and $\$ 7.15$ in 2007 and 2008. In an effort to reduce the number of individuals excluded due to timing or reporting issues, we use the 2006 level in all years.

${ }^{15}$ By applying the probability of job loss to more than those in the bottom decile, the resulting simulated job loss estimates may be slightly higher than those suggested by the CPS estimates for the lowest $10 \%$ of wage earners.

${ }^{16}$ The CEO thresholds use the methods from the National Academy of Science study by Citro and Michael (1995), which includes more expenditures but also more resources, such as in-kind benefits, and incorporates geographic differences in living costs. This results in higher thresholds for New York City than the federal poverty threshold. For example, for a two-adult, two-child family the CEO threshold for 2009 was $\$ 29,477$, compared with a federal threshold of 
$\$ 21,756(\mathrm{CEO}, 2011)$.

${ }^{17}$ In contrast, the longitudinal analysis of data from cities where living wages have been implemented captures differences in effects on family income owing to the distribution of workers - and how they were affected - across families. For a lengthier discussion of this issue in the context of the effects of minimum wages on family incomes see Neumark, Schweitzer, and Wascher (2005).

${ }^{18}$ Note that the vertical scale is different.

${ }^{19}$ The predicted wage increase of $\$ 1.67$ for those earning less than $\$ 10$ an hour who keep their jobs is a $20 \%$ increase. Table 1 shows that $12.9 \%$ of workers at covered sites earn less than $\$ 10$. Thus, the average wage increase for those earning less than $\$ 10$ is $2.6 \%$. Given that the proposed living wage increase is $48.1 \%$ more than the 2006 minimum wage, the implication of the 0.051 wage elasticity we estimate from the CPS is that wages of those in the bottom decile should rise by $2.5 \%$. Thus, although there is not an exact match between the bottom decile and those earning less than $\$ 10$ an hour, the simulation results match the CPS estimate quite well. ${ }^{20}$ See http://www.health.state.ny.us/health_care/medicaid/ (viewed February 8, 2011); http://www.irs.gov/individuals/article/0,,id=96406,00.html (viewed April 5, 2011); http://otda.ny.gov/main/programs/tax-credits (viewed February 8, 2011); and http://www.fns.usda.gov/snap (viewed April 5, 2011).

${ }^{21}$ Because the simulations assume that individuals who continue employment at the living wage will receive an hourly wage of $\$ 10$, we implicitly assume that health benefits are provided. If we were to assume that wages would increase to $\$ 11.50$ per hour because health benefits were not provided, the percent of families eligible for Medicaid benefits would decrease. Offsetting this is the possibility that some employers would stop offering health insurance as a result of the wage 
floor. Note that the Medicaid income thresholds are higher than those for the other programs, especially for families with infants and young children. This may be one explanation for why we see a slight increase in Medicaid eligibility and small decreases in the other programs.

${ }^{22}$ Details are provided at https://www.census.gov/geo/puma/2010_puma_guidelines.pdf(viewed October 2, 2012).

${ }^{23}$ Details and comparisons with living wage laws in other cities are provided in Charles River Associates (2011).

${ }^{24}$ And even this law is still being litigated at the time of writing. 